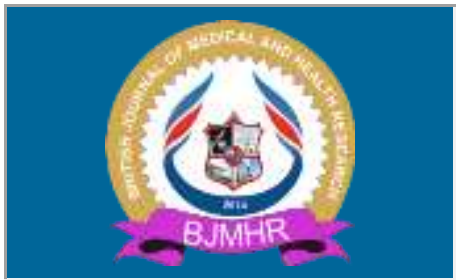

\title{
BJMHR
}

British Journal of Medical and Health Research Journal home page: www.bjmhr.com

\section{Morphometric Study and Embryological Basis of High Termination of Brachial Artery with Clinical Implication in Surgical Interventions.}

\section{Pooja Rani ${ }^{*}$, Anil Kumar ${ }^{2}$, Anudeep Singh ${ }^{3}$ \\ 1.Department of anatomy, Pt. B.D.Sharma, Post Graduate Institute of Medical Sciences, Rohtak, 124001, Haryana, India \\ 2. Department of Anatomy and Neurobiology, College of Medicine and Health Sciences (CoMHS), National University of Science and Technology (NUST), Al Tareef, Post Box no.391, postal code 321, Sohar, Sultanate of Oman. \\ 3.Senior Lecturer, Department of anatomy, International Medical University, Kuala Lumpur, Malaysia.}

\section{ABSTRACT}

It is important for surgeons and anatomists to have an understanding of thickness, diameter and variability of the brachial artery in the upper limb. As the variability of the brachial artery presents, the possibility of frequent vascular injury needs to be considered during a number of surgical and invasive procedures. The present study aims to perform a morphometric assessment of brachial artery with respect to clinical implication of its high termination and correlate it with its embryological basis. Routine dissections of the right and left upper limbs of 36 adult cadavers were done and observed for variations in the branching pattern of brachial artery. The measurement of brachial artery and its level of termination were taken at two levels. The internal and external diameters of the brachial artery along with the thickness of the brachial artery were measured at three different levels. The higher division of termination of brachial artery into ulnar and radial artery was found at mid-arm level. The average length of brachial artery on right and left side was side was $23.39 \mathrm{~cm}$ and $22.36 \mathrm{~cm}$ respectively. The internal and external diameter of brachial artery was significantly larger on right side than left. In addition, the thickness of the middle part of brachial artery on left side was significantly $(\mathrm{P}<0.05)$ larger than the right side.: The present study will enhance clinician's awareness of potential arterial variations and morphometric assessment of brachial artery will help clinicians and surgeons for more accurate diagnostic evaluation and surgical management of vascular injuries and diseases.

Keywords: Brachial artery bifurcation, Radial artery, Ulnar artery, Vascular anomaly Clinical implications, Surgical interventions.

*Corresponding Author Email: drpooja0912@ yahoo.com

Received 05 March 2020, Accepted 19 March 2020

Please cite this article as: Rani P et al., Morphometric Study and Embryological Basis of High Termination of Brachial Artery with Clinical Implication in Surgical Interventions.. British Journal of Medical and Health Research 2020. 


\section{INTRODUCTION}

The brachial artery is a continuation of the axillary artery, originating at distal edge of teres major muscle tendon and enters into cubital fossa accompanying the median nerve. Under the cover of bicipital aponeurosis, it divides into an ulnar artery and radial artery, anteromedial to the neck of the radius. At first it is medial to the humerus, but gradually spirals anterior to it until it lies midway between the humeral epicondyles (Williams et al., 1999). Variations in upper limb arteries are fairly common and have been reported by several authors. Anatomical variations of brachial artery occur in almost $25 \%$ of the cases and are commonly found in routine dissections or clinical practice (Bergman et al., 1988). Brachial artery crossing superficial to median nerve from medial to lateral side in middle one-third $\left(1 / 3^{\text {rd }}\right)$ of arm was called superficial brachial artery (Adachi, 1928). The high division of brachial artery may occur at any point in the normal course of the vessel, and it is more common in the middle third of arm. These variations could affect the success and complication rates of procedures such as cannulation, radial forearm flap surgery, arterial grafting, fasciotomy for compartment syndrome, cardiac catheterization, angioplasty, and orthopedics surgery (Kumka and Purkiss, 2015).

Arteries are muscular and/or elastic cylindrical tubes that conduct blood away from the heart. In respect to their elasticity, arteries can enlarge either in length or in width in order to retain the greatest amount of blood volume possible and to keep the blood flow steady (Petroianu, 1999). According to their internal diameter, they can be classified as large diameter artery (some centimeters to $7 \mathrm{~mm}$ ); medium diameter artery (from $7 \mathrm{~mm}$ to $2.5 \mathrm{~mm}$ ); small diameter artery (from $2.5 \mathrm{~mm}$ to $0.5 \mathrm{~mm}$ ); and arterioles (less than $0.5 \mathrm{~mm}$ ) (Rouviere, 1999; Dangelo and Fattini, 2007). The diameter of major upper limb arteries gives many clues to the management of clinically related problems of humans. It is important that clinicians and anatomists have an understanding of the thickness, diameter and the variability of the brachial artery in the upper limb. As the variability of the brachial artery presents, the possibility of frequent vascular injury has to be considered during a number of surgical and invasive procedures (Malcic-Gurbuz et al., 2002).

Nowadays cardiologists and radiologists are utilizing the brachial artery with increasing frequency for catheter based diagnostic and therapeutic intervention procedures. Blood pressure and pulse Doppler ultra-sonographic measurements are routinely assessed through distal part of brachial artery (Singh et al., 2010). The present study will enhance clinician's awareness of potential arterial variations and morphometric assessment of brachial artery that help clinicians and surgeons for more accurate diagnostic evaluation and surgical management of vascular injuries and diseases. 


\section{MATERIALS AND METHOD}

\section{Experimental design:}

The present study was conducted on 36 embalmed human cadavers with age ranging from 20 to 80 years, irrespective of sex. A total of 72 upper limbs (36 right and 36 left upper limbs) were included in the study conducted in the department of Anatomy, University College of Medical Sciences, Delhi, India, for the period of 3 years from 2011 to 2014. These cadavers were a part of teaching program of First Year Undergraduate M.B.B.S. students at University College of Medical Sciences, Delhi, India.

\section{Exclusion criterion:}

Adult upper limbs showing gross deformity, asymmetry or partially amputated limbs were excluded from the present study.

\section{Ethical approval:}

All procedures performed in the study involving human cadavers were in accordance with the ethical standards of the institutional research committee. The study was approved by Bioethics committee of University College of Medical Sciences, Delhi, India.

\section{Methodology:}

The dissection was carried out to look for the brachial artery and its branches. The dissection was initiated with incision of the skin and subcutaneous tissue using a scalpel directed at a right angle from the corium according to the instruction by Cunningham's manual of practical anatomy (Romanes, 2008). This incision occurred longitudinal to the middle portion, thus the skin was pulled apart and subcutaneous cell tissue and biceps brachii muscle were lateralized in order to observe the brachial artery. The muscles were dissected by removing adipose tissue and fasciae around them. The brachial artery and its branches were exposed after dissection of both upper extremities (right and left) to observe any variation (Romanes, 2008). The origin of brachial artery, its course, branches, and variations if any were carefully observed, identified, photographed. The branching pattern of brachial artery was studied and the variation in its branching pattern were traced, cleaned and noted.

\section{Measurements:}

Brachial arteries were dissected \& traced proximally to the continuity with axillary artery at the level of lower border of teres major. Distally in the cubital fossa, the bicipital aponeurosis was divided and the brachial artery was traced up to its bifurcation. For measuring the length of brachial artery two points were taken. First, the distance between lower border of teres major and intercondylar line was measured along the artery and then the distance between intercondylar line and termination of brachial artery was measured (Figure 1).Then the length of the brachial artery was calculated by adding these two. The thickness, internal diameters, 
and external diameters of the brachial artery were measured at three different levels by using vernier caliper and ruler (Figure 3). Entire measurements were repeated three times by the three different persons, and then average was calculated. The first set of the measurement of brachial artery was taken at its proximal origin just at the lower border of teres major. The second set of the measurement was taken below the Profunda brachii artery (middle of the brachial artery). In the cubital fossa, the third set of the measurement was taken at the bifurcation level. The level of the bifurcation of brachial artery was also determined with respect to the head of radius. The material used in the measurement program included vernier caliper to measure the thickness, internal diameter and external diameter; and ruler to measure the length of the brachial artery (Figure 2). The measurements were taken using vernier caliper $(0.01 \mathrm{~mm}$ accuracy) and data were tabulated.
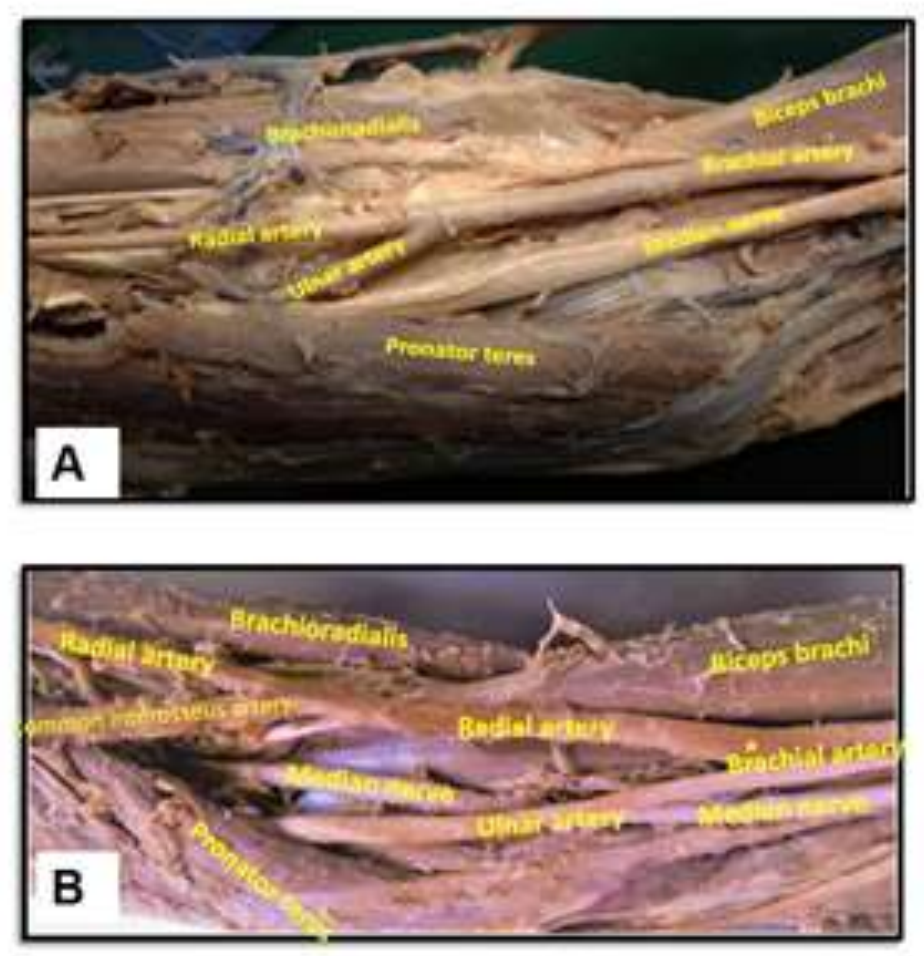

Figure 1: Light photograph of right upper limb showing the normal (A) course and abnormal high bifurcation (B) of brachial artery (Point of bifurcation is shown by yellow $\operatorname{star} *)$. 

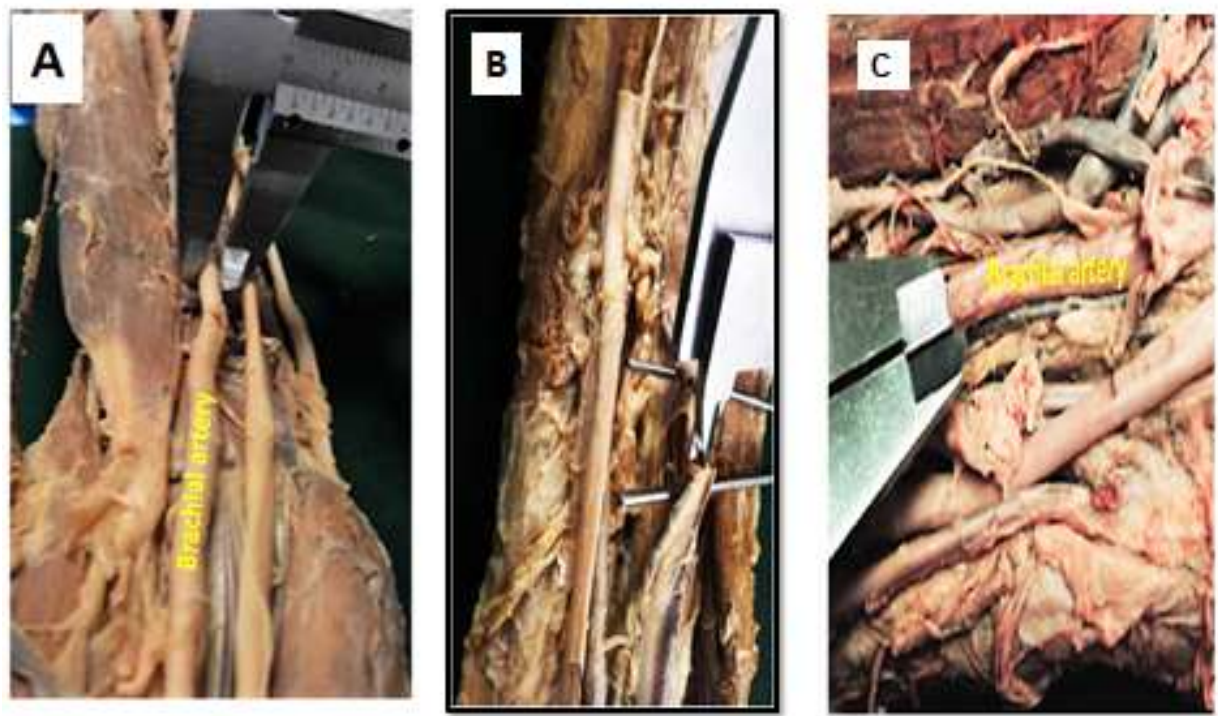

Figure 2: Light photograph of upper limb showing the internal diameter (A), external diameter (B), thickness (C) of brachial artery.
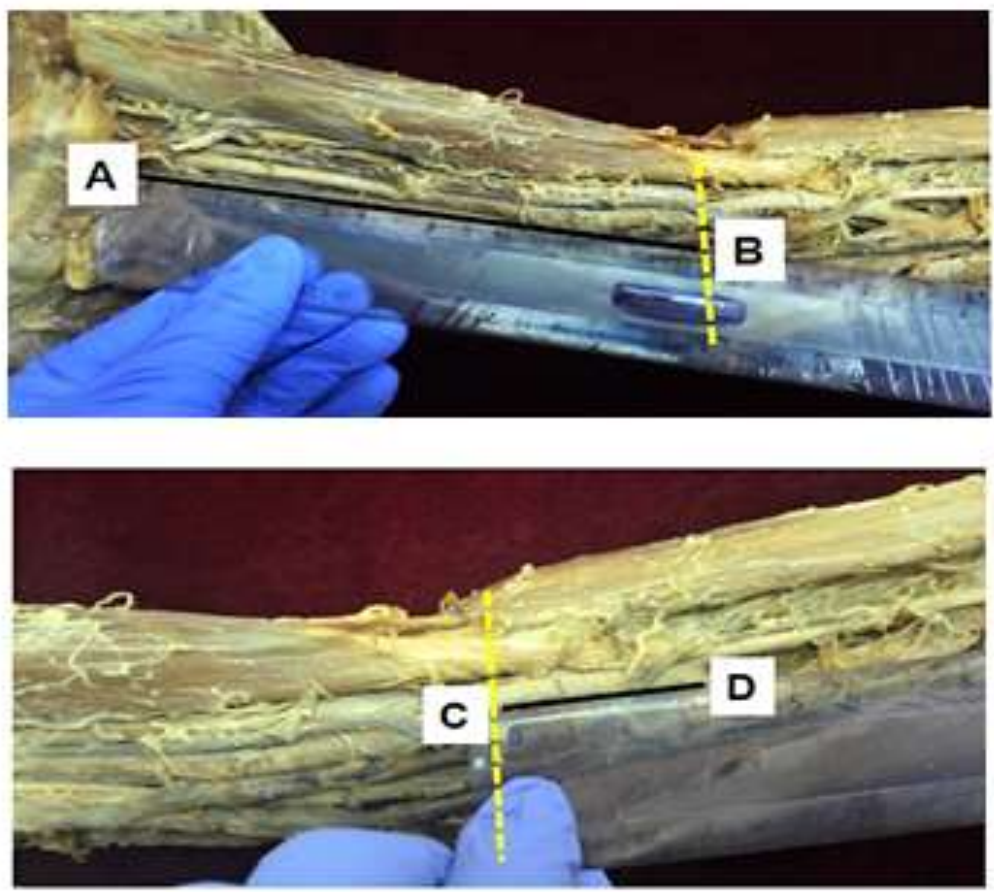

FIGURE 3: Light photograph of right upper limb showing length of brachial artery. ABlength of brachial artery from lower border of teres major to intercondylar line, CDlength of brachial artery from intercondylar line to bifurcation of brachial artery, Dotted (-----) yellow line shows intercondylar line.

\section{Statistical analysis:}

The data was collected and calculated to measure the mean and standard deviation. Student Ttest were performed to assess difference in arterial diameters, thickness, and the length of brachial artery between right and left sides of the upper limb of the cadavers. $\mathrm{P} \leq 0.05$ was considered statistically significant. 
Table 1: Level of termination of brachial artery from intercondylar line

\begin{tabular}{lll}
\hline Range & $\mathbf{1 . 1} \mathbf{- 2} \mathbf{~ c m}$ & $\mathbf{2 . 1} \mathbf{- 4} \mathbf{~ c m}$ \\
\hline Right & 26 & 8 \\
Left & 24 & 10 \\
Total & 50 & 18 \\
\hline
\end{tabular}

Table 2: Distance from intercondylar line to bifurcation of brachial artery

\begin{tabular}{lllll}
\hline & Number & Mean $(\mathbf{c m})$ & S.D & Range (cm) \\
\hline Right & 34 & 1.93 & 0.34 & $1.1-4.0$ \\
Left & 34 & 1.18 & 0.41 & $1.2-3.8$ \\
Total & 68 & 1.55 & 0.37 & $1.1-4.0$ \\
\hline
\end{tabular}

Table 3: The Mean and Standard Deviation (SD) of external diameter, internal diameter, and thickness of the brachial artery

\begin{tabular}{lllll}
\hline Side & Site & Mean (SD) & & \\
\cline { 3 - 5 } & & External Diameter & Internal Diameter & Thickness \\
\hline Left & Proximal & $6.23(1.33)$ & $6.03(1.23)$ & $0.22(0.41)$ \\
& Middle & $5.14(1.09)$ & $4.53(0.74)$ & $0.19(0.21)$ \\
& Bifurcation & $5.46(1.11)$ & $4.78(0.68)$ & $0.21(0.07)$ \\
Right & Proximal & $6.92(1.91)$ & $6.32(1.81)$ & $0.21(0.04)$ \\
& Middle & $5.34(1.30)$ & $4.76(0.81)$ & $0.16(0.19)$ \\
& Bifurcation & $5.59(1.16)$ & $5.11(0.71)$ & $0.24(0.14)$ \\
\hline
\end{tabular}

Table 4: Prevalence of higher division of bifurcation of brachial artery

\begin{tabular}{llll}
\hline S.No. & Name of the author & Year & Percentage $(\%)$ \\
\hline 1. & Gruber & 1848 & 0.4 \\
2. & Muller & 1903 & 1.0 \\
3. & Linell & 1921 & 6.0 \\
4. & Adachi & 1928 & 0.1 \\
5. & DeGaris and Swartley & 1928 & 9.0 \\
6. & Miller & 1939 & 3.0 \\
7. & McCormack et al & 1953 & 5.8 \\
8. & Keen & 1961 & 12.3 \\
9. & Fuss et al & 1985 & 17.0 \\
10. & Baeza et al & 1995 & 11.9 \\
11. & Kapur et al & 2000 & 5.0 \\
12. & Rodriguez et al & 2001 & 0.2 \\
13. & Patnaik et al & 2002 & 6.0 \\
14. & Yang et al & 2003 & 12.2 \\
15. & Kachlik et al. & 2011 & 5.0 \\
16. & Pulei A et al & 2012 & 6.1 \\
17. & Present study & 2013 & 2.9 \\
\hline
\end{tabular}

\section{RESULTS:}

In present study, all brachial arteries $(72 \mathrm{~N})$ were in the anatomical position. The brachial artery was at first medial to the humerus and then gradually spiraled anterior to it, reaching the midpoint of the cubital fossa, lateral to the median nerve. Within the cubital fossa, the brachial artery was located centrally and divided near the neck of the radius into its terminal branches as radial and ulnar arteries (Figure 1). The brachial artery bifurcated at different level distal to 
the intercondylar line of humerus in $97.1 \%$ cadavers. The distance of level of bifurcation of brachial artery into radial and ulnar arteries from the intercondylar line of humerus in both sides is shown in Table 1. In only one cadaver the brachial artery was crossing superficial to median nerve from medial to lateral side and then bifurcated into two branches at mid-arm level (Figure 1), measuring $18.3 \mathrm{~cm}$ from cubital fossa. Contrary to what is typically seen, the radial artery in this cadaver was the main branch of brachial artery and therefore larger than usual. In this specimen (cadaver) the length of brachial artery was $7.4 \mathrm{~cm}$, radial artery $33.4 \mathrm{~cm}$, ulnar artery $23.5 \mathrm{~cm}$. The prevalence of the higher termination of brachial artery above the intercondylar line of humerus was found to be $2.9 \%$ in the present study.

On the right side, the average length of brachial artery from lower border of teres major to the intercondylar line was $21.41 \mathrm{~cm}$, from the intercondylar line to the bifurcation was $1.93 \mathrm{~cm}$ and the total average length of brachial artery was noted as $23.39 \mathrm{~cm}$. Whereas, on the left side, the average length of brachial artery from lower border of teres major to the intercondylar line was $20.80 \mathrm{~cm}$, from the intercondylar line to the bifurcation was $1.18 \mathrm{~cm}$ and the total average length of brachial artery was $22.36 \mathrm{~cm}$. The mean value of length of brachial artery on right side and left side was not statistically significant $(\mathrm{P}>0.05)$. The mean distance from intercondylar line of the humerus to the bifurcation of brachial artery which was $1.55 \mathrm{~cm}$ with a range of 1.1 to $4.0 \mathrm{~cm}$ with standard deviation of 0.37 (Table- 2). Among the 72 upper limbs studied, few brachial arteries showed mild deviation from the normal bifurcation level. It ranged from 1.5 to $2 \mathrm{~cm}$ just below the neck of the radius.

The internal diameter, external diameter and thickness of the brachial artery in its proximal, middle and distal parts for both sides of upper limbs were measured (Table 3). On both the sides, there was gradual change in size of both internal and external diameter, with decreasing in the middle part and becoming larger again in the distal part. The brachial artery diameter was significantly larger on right side than left side (Table 3). Similarly, there was gradual change in the thickness of brachial artery of both sides, with decreasing in the middle part and becoming larger again in the distal part. In addition, the left side thickness of the middle part was statistically significantly $(\mathrm{P}<0.05)$ larger than the right side.

\section{DISCUSSION:}

The average length of brachial artery on right side was $21.41 \mathrm{~cm}$ and on left side was 20.80 $\mathrm{cm}$, from lower border of teres major to the intercondylar line. The average length of brachial artery from the intercondylar line to the bifurcation was $1.93 \mathrm{~cm}$ on right side and was $1.18 \mathrm{~cm}$ on left side. The mean value of length of brachial artery on right side and left side was not statistically significant $(\mathrm{P}>0.05)$. Patnaik et al. (2001) reported the average length of brachial artery from the lower border of teres major and intercondylar line was $23.2 \mathrm{~cm}$, below 
intercondylar line and bifurcation of brachial artery was $2.99 \mathrm{~cm}$, and the total length of brachial artery was $26.29 \mathrm{~cm}$.

The present study focused on morphology including both internal and external diameter and thickness of the proximal, middle and distal part of brachial artery. Kian et al. (2012) opined that, on ultrasound study, the success rate of artificial arteriorvenous fistula for hemodialysis purpose is increased as the internal diameter of artery is more than $0.16 \mathrm{~mm}$. In present study, the internal diameter $(\mathrm{mm})$ of brachial artery at proximal (left 6.03 and right 6.32), at middle (left 4.53 and right 4.76), and at distal (left 4.78 and right 5.11). The external diameter (mm) of the brachial artery at proximal (left 6.23 and right 6.92), at middle (left 5.14 and right 5.34) and at distal (left 5.46 and right 5.59). The thickness of the brachial artery on the left side at proximal $(0.22)$, at middle $(0.19)$, distal $(0.21)$. The thickness on the right side at proximal $(0.21)$ at middle (0.16) at distal (0.21). In both sides, there is gradual change of size of external diameter and thickness of brachial artery, with decreasing in the middle part and becoming larger again in the distal part. Therefore, based on external diameter and thickness of the brachial artery the proximal part is the common site for artificial fistula to connect the artery to vein.

The mean length of brachial artery bifurcating into radial and ulnar arteries below intercondylar line was $1.55 \mathrm{~cm}$ (ranging from 1.1 to $4.0 \mathrm{~cm}$ ). In present study, in $97.1 \%$ of cadavers bifurcation into ulnar and radial arteries occurred at different level distal to the intercondylar line of humerus in the brachial artery, whereas it was shown as 95\% in United Kingdom population and $91.7 \%$ in Indian population (Vandana et al. , 2012).

The bifurcation of the brachial artery when proximal to intercondylar line is referred to as a high division, which has been reported by series of studies (Moore and Persaud, 1999; Celik et al., 2001; Patnaik et al., 2001; Quarrat et al., 2002; Cherukupalli et al., 2008; Sathynarayan et al., 2010; Singh et al., 2010). In our study, only one cadaver showed the higher bifurcation of brachial artery. In this specimen, the brachial artery continued from axillary artery at the lower border of teres major and crossed superficial to median nerve from medial to lateral side. Adachi (1928) reported crossing of brachial artery superficial to median nerve from medial to lateral side as superficial brachial artery. The brachial artery then bifurcated into its two terminal branches at mid-arm level which was $18.3 \mathrm{~cm}$ from cubital fossa. The level of bifurcation was proximal to the intercondylar line of humerus and classified as high bifurcation of the brachial artery. Vandana et al. (2012) observed that the higher bifurcation of brachial artery was found in 5\% of Indian population and in 3\% of United Kingdom population. The high brachial artery bifurcation is most common vascular variation of the upper limb (Mccormack et al., 1953; Rodriguez-Niedenfuhr et al., 2001). The presence of these arterial variations may be due to chemical factors, hemodynamic forces, fetal position in the uterus, 
genetic predisposition and the result of developmental anomaly during the formation of blood vessels (Vandana et al., 2012).

\section{Prevalence of high bifurcation (Table 4):}

Bertolazzo (1981) reported high bifurcation of the brachial artery is rare, found in only $0.5 \%$ samples in 202 cadavers dissected. The incidence of the superficial brachial artery varies from $3.6 \%$ to $9.6 \%$ (Keen, 1961; Wankoff, 1962; Fuss et al., 1985; Matula et al. 1990). In present study, the prevalence of the higher termination of brachial artery was seen in $2.9 \%$ of cadavers at mid-arm level in right upper limb only. In another study involving 72 upper limbs of Brazilian adult cadavers, only $11.1 \%$ cases of high division of brachial artery were reported by Olave et al. (1997). Quarrat-Ul-Ain et al. (2002) observed high division of brachial artery in two limbs out of 88 upper limbs of dissected cadavers. Rossi Junior et al. (2011) conducted a study on 56 cadavers in which they encountered a case of high division of the brachial artery, located in the upper $1 / 3$ rd in both arms in a male cadaver (1.78\%).

\section{Embryological basis of high bifurcation:}

The early limb bud receives blood via inter segmental arteries, which contribute to a primitive capillary plexus. At the tip of the limb bud there is a terminal plexus that is constantly renewed in a distal direction as the limb grows and later only one main vessel left which supplies the upper limb bud which is termed as axis artery (brachial). The ectodermal-mesenchymal interactions and extracellular matrix components are controlling the initial patterning of blood vessels within the limb (Keith and Persaud, 2008). In the upper limb bud the axis artery is derived from the lateral branch of the seventh inter segmental artery (subclavian). The arterial trunk grows outwards along the ventral axial line and terminates in the deep plexus in the developing hand. Proximal part of the main trunk forms the axillary and brachial artery and its distal part persists as the anterior interosseus artery and the deep palmer arch. The radial and ulnar arteries are the last arteries to appear in the forearm from the axis artery. Initially the radial artery arises more proximally than the ulnar artery. Later, it establishes a new connection with the main trunk at or near the level of origin of the ulnar artery and the upper portion of its original stem usually disappears to a large extent more proximally from the brachial artery leading to the formation of an unusually short segment and slightly narrow brachial artery which bifurcates into radial and ulnar arteries at a more proximal level near the middle of the arm leading to high level of bifurcation (Baeza, 1995).

\section{Clinical significance of high bifurcation:}

The high level of bifurcation of brachial artery has been accounted to be predictor of brachiocephalic fistula failure and commonest site for embolism which would result in an area of ischemia. Knowledge of variations in the course and higher termination of the brachial artery are of great importance in arteriovenous fistulae, aneurysms and abcess drainage in region of 
axilla, arm and cubital fossa (Taub et al.,1999), cardiac catheterization for angioplasty and arterial grafting (Lioupis et al., 2010; Kirksey, 2012; Cherukupuli et al., 2008). GonzalezCompta (1992) highlighted the diagnostic, interventional and surgical significance of such a vascular variation. Diagnostically, it may disturb the evaluation of angiographic images. Interventional, accidental puncture of superficially placed arteries may occur while attempting venipuncture. Surgically, it is vulnerable in both orthopedic and plastic surgery operations.

Another clinical application of the brachial artery is the measurement of its flow mediated dilation (FMD), a method of evaluating endothelial function used in obstetrics according to the study performed by Brandao, Lopes, Peres et al. (2010). Whenever femoral access is not possible in ventriculography, brachial artery is the artery of choice. The best access choice for hemodialysis is a primary upper limb arteriovenous fistula involving the radial artery and the cephalic vein in wrist region, as described by Brescia et al. (1966), quoted by (Correa, Pires, Kafejian et al., 2005). Undoubtedly, such variations are important for radiologists, vascular surgeons and orthopedists for more precise diagnostic evaluation and more secure surgical management of vascular diseases and injuries.

\section{CONCLUSION}

The anatomic knowledge of the vascular patterns of upper limb is of crucial importance for more accurate diagnostic interpretation and surgical treatment, not only for neurosurgeons but for all those involved in radiodiagnostics particularly in cases involving traumatic injuries. So the surgeons should be aware of arterial variations in the region before embarking on the procedure. The present study will prove useful to the neurosurgeons, interventionists, radiologists and clinicians for diagnostic evaluation and surgical management of vascular injuries and diseases.

\section{ACKNOWLEDGEMENT}

We acknowledge and are thankful for the support provided by Dr. Veena Bharihoke, Head of Department of Anatomy, University College of Medical Sciences, Delhi, India.

\section{REFERENCES:}

1. Adachi B. Das Arterian system des japaner (the arterial system of japanese). Kyoto. 1928;1:205-210.

2. Baeza AR, Nebot J, Ferreira B, Reina F, Perez J, Sanudo JR, Roig M. An anatomical study and ontogenetic explanation of 23 cases with variations in the main pattern of the human brachio-antebrachial arteries. J Anat.1995;187(2):473-479.

3. Bergman RA, Thompson SA, Afifi AK, Saadeh FA. Compendium of human anatomic variation. Baltimore: Urban \& Schwarzenberg, 1988. 
4. Bertolazzo W, Romero AM, Bica DT, Cavalheiro FC, Barroso-Filho F, Pezzi LH, Kauffman L. Variaçao anatomica da arteria braquial bifurcaçao alta. Rev. Bras. Cir. 1981;71(3):173-180.

5. Celik HH, Gormus G, Aldur MM, Ozcelik M. Origin of the radial and ulnar arteries: variation in 81 arteriograms. Morphologie, 2001;85(269):25-27.

6. Cherukupuli C, Dwivedi A, Dayal R. High bifurcation of brachial artery with acute arterial insufficiency: a case report. Vasc. Endovasc. Surg. 2008;41(6):572-574.

7. Dangelo JG and Fattini CA. Anatomia humana sistemicae segmentar. 2th ed. Sao Paulo: Atheneu, 2007.

8. Degaris CF and Swartley WB. The axillary artery in white \& Negro stocks. Am. J Anat. 1928;41: 353-597.

9. Fuss FK, Matula CW, Tschabitscher M. Die Arteria brachialis superficialis. Anatomischer Anzeiger. 1985;(160):285-294.

10. Gonzalez-Compta X. Origin of the radial artery from the axillary artery and associated hand vascular anomalies. J Hand Surg. Am. 1991;16(2):293-296.

11. Gruber W. Brachial and antebrachial arterial patterns. Surgery Gynaecology obstetrics.1848; 96: 43-54.

12. Junior R, Esteves, Simoes JS, Fernandes GJM. Bilateral high division of the brachial artery in one human male cadaver: a case report. J Morphol Sci. 2011;28(3):204-207.

13. Kachlik D, Konarik M, Baca V. Vascular patterns of upper limb: an anatomical study with accent on superficial brachial artery. Bos J Basic Med Sci. 2011; 11(1): 4-10.

14. Kapur V, Suri RK, Manik P, Dhir V. Surgical anatomy of median nerve. J Anat. Soc. India. 2000;49(1): 92

15. Keen JA. A study of the arterial variations in the limbs with special reference to symmetry of vascular patterns. Am J Anat. 1961;(108):245-261.

16. Keith LM, Persaud TVN. The developing human - Clinically oriented embryology. Elsevier publications, 2008, $8^{\text {th }}$ edition, 371-374.

17. Kian K, Shapiro JA, Salman L, Khan RA, Merrill D, Garcia L, Eid N, Asif A, Aldahan A, Beathard G. High brachial artery bifurcation: clinical considerations and practical implications for an arteriovenous access. Seminar in Dialysis. 2012;25(2):244-247.

18. Kirksey L. Unrecognized high brachial artery bifurcation is associated with higher rate of dialysis access failure. Seminars in Dialysis. 2012;24(6):698-702.

19. Kumka M, Purkiss S. A rare case of unilateral variations of forearm arteries: anatomy, embryology and clinical Implications. J Can Chiropr Assoc. 2015;59(3):253-260.

20. Lanz T. and Wachsmuth W. Praktische Anatomie. Vol. I Part B. Arm Springer Berlin. $1959 ; 124-25$ 
21. Linell EA. The distribution of the nerves in upper limb with reference to variability \& their clinical significance. J Anat. 1921;55:79.

22. Lioupis C, Mistry H, Junghans C, Haughey N, Freedman B, Tyrrell M, Valenti D. High brachial artery bifurcation is associated with failure of brachiocephalic autologous arteriovenous fistulae. J Vas. Acc. 2010;11(2):132-137.

23. Lipper H. \& Pabst R. Arterial variations in man. Springer, New York. 1985;68-73.

24. Malcic-Gurbuz J, Gurunluogl R, Ozdogmus O, Yalin A. Unique case of trifurcation of the brachial artery: its clinical significance. Clin. Anat. 2002;15(3):224-227.

25. Matula CW, Fuss FK, Tschabitscher M, Hold M. Die grossen Arterien der Cubita. Uber ihre Herkunft am oberarm und deren Fortsetzung auf den Unterarm. Angio. Archiv. 1990;(19):193-195.

26. Mccormack LJ, Cauldwell EW, Anson BJ. Brachial and antebrachial arterial patterns; a study of 750 extremities. Surgery, Gynecology \& Obstetrics, 1953:96(1):43-54.

27. Miller RA. Observations upon the arrangement of axillary artery \& brachial plexus. Am. J Anat. 1939;64: 143-63.

28. Moore KL, Persaud TVN. The limbs developing human: clinically oriented embryology. 6th ed. India: Harcourt Asia. 1999:442-444.

29. Muller. Die Aron-Arterian des Menschen. Anat Hefte. 1903;22:379.

30. Olave E, Braga MTT, Gabrielli C, Rodrigues CFS. Nivel de bifurcacion de la arteria braquial y sus relaciones conel nervio mediano. Rev. Chil. Anat. 1997;15(1):99-105.

31. Patnaik VVG, Kalsey G, Singla RK. Trifurcation of brachial artery: a case report. J Anat. Soc. India. 2001;50(2):163-165.

32. Pulei A, Obimbo M, Ongeti K, Kitunguu P, Inyimili M, Ogeng'o J. : Surgical significance of brachial arterial variants in a Kenyan population. Annals of African Surg. 2012;9:32-36.

33. Quarrat UL, Kauser Y, Raza TA. High division of brachial artery and analogus? Start of radial and ulnar arteries. Annals of King Edward Medical College. 2002;8(1):30-31.

34. Rodriguezniedenfu MHR, Vazquez T, Nearn L, Ferreira B, Parkin I, Sanudo JR. Variations of the arterial pattern in the upper limb revisited: a morphological and statistical study, with a review of the literature. J Anat. 2001;199:547-566.

35. Romanes GJ. The anterior Compartment of Arm. Cunningham's Manual of Practical Anatomy, Volume 1(Upper limb and Lower limb).Oxford Publication. 2008;15:67-70.

36. Rouviere H. Anatomia humana descritivae topografica. Madri: Casa editorial baillybailliere, 1956. 
37. Sathynarayan N, Sunitha P, Shaik MM, Devi PSV. Brachaial artery with high up division with its embryology basis and clinical significance. International Journal of Anatomical Variations. 2010;(3):56-58.

38. Singh H, Gupta N, Bargotra RN, Singh NP. Higher bifurcation of brachial artery with superficial course of radial artery in forearm: case report. JK Science. 2010;12(1)3940.

39. Taub J, Giannikis G, Shen HY, and Kim U. The Brachial artery transection following closed elbow dislocation. J. Trauma. 1999;47(1):176-178.

40. Treves FB and Rogers L. Surgical applied anatomy In: The upper extremity. 11th Edn. Cassell \& Co. Ltd. London. 1947;247.

41. Vandana R, Suresh NM, Prabha LR, Pai V. Variation in course and branching pattern of brachial artery. Anatomica Karnataka. 2012;6(3):42-48.

42. Wankoff W. Uber einige Gesetzmabigkeiten bei der Variabilitat der Arterien der oberen Extremitat. Anatomischer Anzeiger. 1962;(111):216-240.

43. Williams PL, Bannister LH, Berry MM, Collins P, Dyson M, Dussek JE, Ferguson MW, eds. Gray’s Anatomy. 38th Ed., London, Churchill Livingstone. 1999;319:1539.

44. Yang HJ, Gil YC, Jung WS, Lee HY Variations of the superficial brachial artery in Korean Cadavers. J Kor. Med. Sci. 2008;23:884-887.

\section{BJMHR is}

- Peer reviewed

- Monthly

- Rapid publication

- Submit your next manuscript at editor@bjmhr.com 